\title{
RANCANG BANGUN HUMAN ACTIVITY RECOGNIZER SEBAGAI CLASSIFIER SINYAL GEMPA BUMI DAN AKTIVITAS MANUSIA PADA AKSELEROMETER SMARTPHONE
}

\author{
Haryas Subyantara Wicaksana \\ Program Studi Instrumentasi MKG \\ Sekolah Tinggi Meteorologi Klimatologi dan Geofisika \\ Email: haryassubyan@gmail.com \\ Hapsoro A. Nugroho \\ Program Studi Instrumentasi MKG \\ Sekolah Tinggi Meteorologi Klimatologi dan Geofisika \\ Email: hapsoro.agung@bmkg.go.id
}

\begin{abstract}
ABSTRAK
Akselerometer pada smartphone dapat merekam sinyal gempa bumi guna mendukung mitigasi kebencanaan di Indonesia. Aktivitas manusia menghasilkan noise yang cukup signifikan terhadap data akselerometer pada smartphone. Human Activity Recognizer (HAR) diimplementasikan memilah sinyal aktivitas manusia dari sinyal gempa bumi yang direkam akselerometer smartphone. Penelitian ini bertujuan untuk mengklasifikasikan sinyal percepatan linier aktivitas manusia dengan sinyal percepatan gempa bumi pada akselerometer smartphone Android melalui Human Activity Recognizer (HAR) berbasis algoritma K-Nearest Neighbor (K-NN). Metode penelitian terdiri dari penghimpunan data, pra pengolahan data, segmentasi data, ekstraksi ciri, dan klasifikasi. Berdasarkan hasil pengujian HAR sebagai classifier sinyal gempa bumi dan sinyal aktivitas manusia menggunakan algoritma K-NN secara umum mampu memilah sinyal akselerometer smartphone akibat aktivitas manusia dan sinyal gempa bumi dengan rentang akurasi $66,9 \%$ hingga $100 \%$. Algoritma tipe Fine K-NN memiliki akurasi tertinggi sebesar $100 \%$.
\end{abstract}

Kata kunci: akselerometer; smartphone; gempa bumi; human activity recognizer; $k$-nearest neighbor.

\section{ABSTRACT}

Smartphone accelerometers can be used to record earthquake signals to resolve disaster mitigation in Indonesia. Human activity produces significant noise towards accelerometer data on smartphones. One branch of artificial intelligence, namely Human Activity Recognizer (HAR), is very likely to be implemented to sort signals of human activity from earthquake signals recorded by smartphone accelerometers. This study aims to classify linear acceleration signals of human activity with accelerated earthquake signals on the Android smartphone accelerometer through the Human Activity Recognizer (HAR) based on the KNearest Neighbor (K-NN) algorithm. The research method consists of data collection, data preprocessing, data segmentation, feature extraction, and classification. Based on the results of HAR testing as an earthquake signal classifier and signal of human activity obtained that the K-NN algorithm is generally able to sort smartphone accelerometer signals due to human activity and earthquake signals with an accuracy range of $66.9 \%$ to $100 \%$. The Fine K-NN type algorithm has the highest accuracy of $100 \%$.

Keywords: accelerometer; smartphone; earthquake; human activity recognizer; $k$-nearest neighbor.

\section{PENDAHULUAN}

Sensor akselerometer smartphone Android dapat dimanfaatkan sebagai instrumen perekam parameter kegempaan di Indonesia. Namun, gagasan ini memiliki kendala, terutama terkait noise. Aktivitas manusia menghasilkan noise yang cukup signifikan terhadap data akselerometer pada smartphone. Salah satu cabang artificial intelligence, yaitu Human Activity Recognizer (HAR), sangat mungkin diimplementasikan memilah sinyal aktivitas manusia dari sinyal gempa bumi yang direkam akselerometer smartphone.

Gempa bumi adalah peristiwa bergetarnya permukaan bumi di area tertentu karena pergeseran atau pergerakan lapisan batuan pada litosfer akibat penyesaran [1]. Percepatan merupakan perubahan kecepatan dalam rentang waktu tertentu akibat adanya perpindahan posisi dari suatu objek. Sinyal gempa bumi yang direkam akselerometer adalah berupa sinyal percepatan tanah.

Akselerometer merupakan sensor yang berfungsi mendeteksi nilai percepatan suatu objek. Akselerometer tipe LSM6DSL tergolong sensor inersia yang terpasang dalam smartphone Android menggunakan teknologi Micro- 
Electro-Mechanical-System (MEMS). Sensor ini mengukur nilai percepatan linear pada tiga sumbu koordinat kartesian yaitu $\mathrm{x}$, y dan $\mathrm{z}$. Terdapat beberapa jenis input sinyal akselerometer tipe MEMS antara lain sinyal percepatan gravitasi, percepatan akibat aktivitas manusia, offset dan noise [6].

Setiap hari, manusia selalu beraktivitas secara fisik. HAR adalah salah satu cabang berbasis artificial intelligence yang bertujuan mengenali aktivitas manusia melalui pendekatan komputasi perangkat teknologi yang dimanfaatkan oleh manusia [3]. HAR memiliki berbagai metode antara lain menggunakan visualisasi kamera atau sensor inersia seperti akselerometer dan giroskop [4]. Sensor inersia dapat dipasang di area dada, pergelangan tangan, pinggang, maupun paha [5].

K-Nearest Neighbor (K-NN) adalah classifier yang bekerja dengan menghitung jarak suatu input data baru terhadap K-data model pembelajaran. Algoritma ini disebut juga mencari tetangga terdekat dari suatu input data baru [6]. Jarak kedekatan data input baru terhadap data model umumnya dihitung menggunakan persamaan Euclidean Distance [7] sebagai berikut:

$$
E(A, B)=\sum_{i=1}^{N} \sqrt{\left(A_{i}-B_{i}\right)^{2}}
$$

Pada persamaan tersebut, E merupakan jarak input dengan tetangga terdekat, A merupakan data input baru, sedangkan B merupakan data model pembelajaran. Proses perhitungan menggunakan aplikasi MATLAB. Data input baru diuji terhadap setiap titik data pembelajaran, kemudian dicari urutan tetangga dengan nilai jarak terkecil sesuai bilangan K. $K-N N$ memiliki beberapa jenis algoritma pengerjaan [8], yaitu:

a. Fine K-NN, algoritma K-NN menggunakan satu tetangga terdekat $(\mathrm{K}=1)$.

b. Medium K-NN, algoritma K-NN menggunakan sepuluh tetangga terdekat $(\mathrm{K}=10)$.

c. Coarse K-NN, algoritma K-NN menggunakan seratus tetangga terdekat $(\mathrm{K}=100)$.

d. Cosine K-NN, algoritma K-NN yang menggunakan perhitungan jarak tetangga terdekat berbasis cosine distance metrix.

e. Cubic K-NN, algoritma K-NN yang menggunakan perhitungan jarak tetangga terdekat berbasis cubic distance metrix.

Penelitian ini bertujuan untuk mengklasifikasikan sinyal percepatan linier aktivitas manusia dengan sinyal percepatan gempa bumi pada akselerometer smartphone Android melalui HAR berbasis algoritma K-NN. Penelitian ini diharapkan dapat meningkatkan kualitas informasi pasca-gempa dalam bidang mitigasi bencana.

\section{METODOLOGI PENELITIAN}

Perancangan HAR berbasis sensor akselerometer triaksial tunggal terdiri dari beberapa tahapan yaitu penghimpunan data, data preprocessing, segmentasi data, ekstraksi fitur, dan klasifikasi. Gambar 1 menunjukkan diagram alir HAR secara umum. Tahap awal perancangan adalah melakukan penghimpunan data untuk setiap jenis klasifikasi sinyal. Tahap berikutnya adalah menerapkan high pass filter untuk memisahkan sinyal yang dihimpun dari sinyal percepatan gravitasi. Selanjutnya, sinyal dibagi menjadi beberapa segmen. Setelah itu, sistem akan mengekstraksi fitur setiap segmen sinyal dalam domain waktu serta domain frekuensi. Setiap segmen sinyal tersebut kemudian diklasifikasikan sesuai jenis sinyal menggunakan K-NN melalui serangkaian proses training data. Nilai akurasi yang memiliki nilai akurasi tertinggi diekspor menjadi pemodelan prediktor sinyal input yang baru. Tahap akhir perancangan HAR adalah menampilkan hasil klasifikasi sinyal

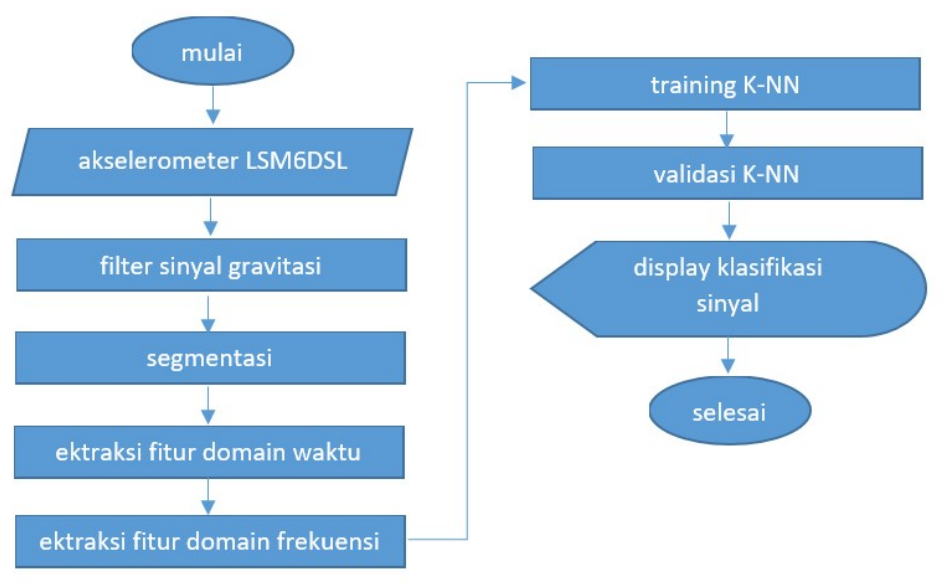

Gambar 1. Diagram Alir HAR 


\subsection{Penghimpunan Data}

Penghimpunan data dilakukan dengan merekam sinyal akselerometer smartphone saat subjek melakukan aktivitas. Jumlah subjek penelitian sebanyak 4 orang, dengan variasi jenis kelamin laki-laki 2 orang dan perempuan 2 orang dengan usia 12 - 22 tahun. Setiap subjek melakukan aktivitas berupa berdiri, berjalan, berlari, duduk, berbaring, melompat, naik tangga, turun tangga, dan bersepeda. Setiap aktivitas diujikan untuk peletakkan smartphone pada saku baju bagian dada dan saku celana bagian paha dengan orientasi peletakan vertikal. Sinyal pemindahan posisi smartphone oleh tangan juga direkam dengan gerakan bebas sebagaimana penggunaan smartphone sehari-hari. Perekaman sinyal ini selanjutnya diklasifikasikan sebagai sinyal non-HAR. Sementara itu, sinyal input gempa bumi yang dihimpun bervariasi dengan magnitudo 4,5 Mw hingga $7 \mathrm{Mw}$.

\subsection{Penerapan High Pass Filter Sinyal Percepatan Gravitasi}

High pass filter dirancang untuk memisahkan sinyal percepatan linier pergerakan aktivitas subjek dari sinyal percepatan gravitasi. Filter ini merupakan highpass filter tipe Butterworth orde 3 dengan frekuensi cut-off $0,1 \mathrm{~Hz}$. Orde 3 dianggap cukup efektif dalam mereduksi sinyal percepatan gravitasi yang memiliki frekuensi dominan berkisar $0,1 \mathrm{~Hz}-0,5 \mathrm{~Hz}$ [5].

\subsection{Segmentasi Data}

Segmentasi data untuk ekstraksi HAR menggunakan 100 sampel tanpa overlapping [9]. Segmentasi tanpa overlapping memiliki akurasi yang lebih baik dibanding dengan overlapping. Frekuensi sampling akselerometer tipe LSM6DSL sebesar $100 \mathrm{~Hz}$, sehingga terdapat 100 sampel per detik. Pada penelitian ini, segmentasi data dilakukan dengan membagi sinyal akselerometer smartphone dengan 100 sampel atau durasi per segmen sepanjang 1 detik tanpa overlapping.

\subsection{Ekstraksi Fitur Sinyal}

Fitur setiap segmen sinyal pada ketiga sumbu akselerometer smartphone akan diekstraksi. Fitur sinyal dalam domain waktu meliputi mean, median, maksimum, minimum, signal magnitudo area, skewness dan kurtosis. Fitur sinyal dalam domain frekuensi meliputi energi spektral, spectral centroid, entropi dan frekuensi dominan.

\subsection{Klasifikasi Sinyal}

Klasifikasi sinyal output percepatan linier aktivitas manusia pada akselerometer triaksial smartphone menggunakan classifier berbasis K-NN. Sebanyak $70 \%$ data digunakan sebagai data model, sedangkan $30 \%$ data digunakan sebagai data validasi melalui proses training. Hasil akurasi classifier tertinggi akan dijadikan sebagai prediktor HAR untuk sinyal input yang baru. Akurasi model classifier dapat ditentukan melalui persamaan berikut [10]:

$$
\text { Akurasi }=\frac{T P+T N}{T P+F P+F N+T} \times 100 \%
$$

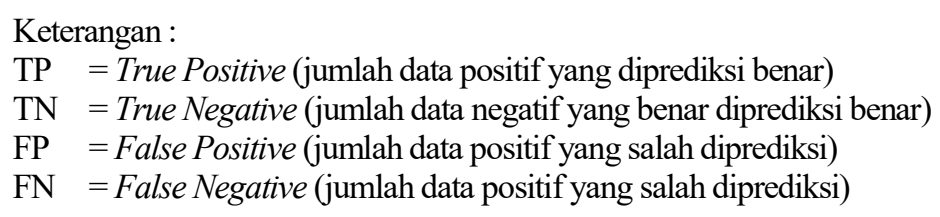

\section{HASIL DAN PEMBAHASAN}

Hasil penghimpunan data menunjukkan bahwa sinyal akselerometer smartphone memiliki pola tertentu untuk setiap jenis aktivitas manusia. Pola ini bersifat identik untuk subjek yang berbeda, tetapi tidak identik untuk penempatan smartphone yang berbeda. Sinyal percepatan linear akselerometer smartphone pada saku celana memiliki amplitudo yang lebih besar dibandingkan dengan sinyal pada saku baju. Hal ini disebabkan oleh pergerakan kaki yang lebih dominan dibandingkan dengan pergerakan dada saat manusia beraktivitas. Gambar 2 dan 3 membuktikan analisis tersebut. 


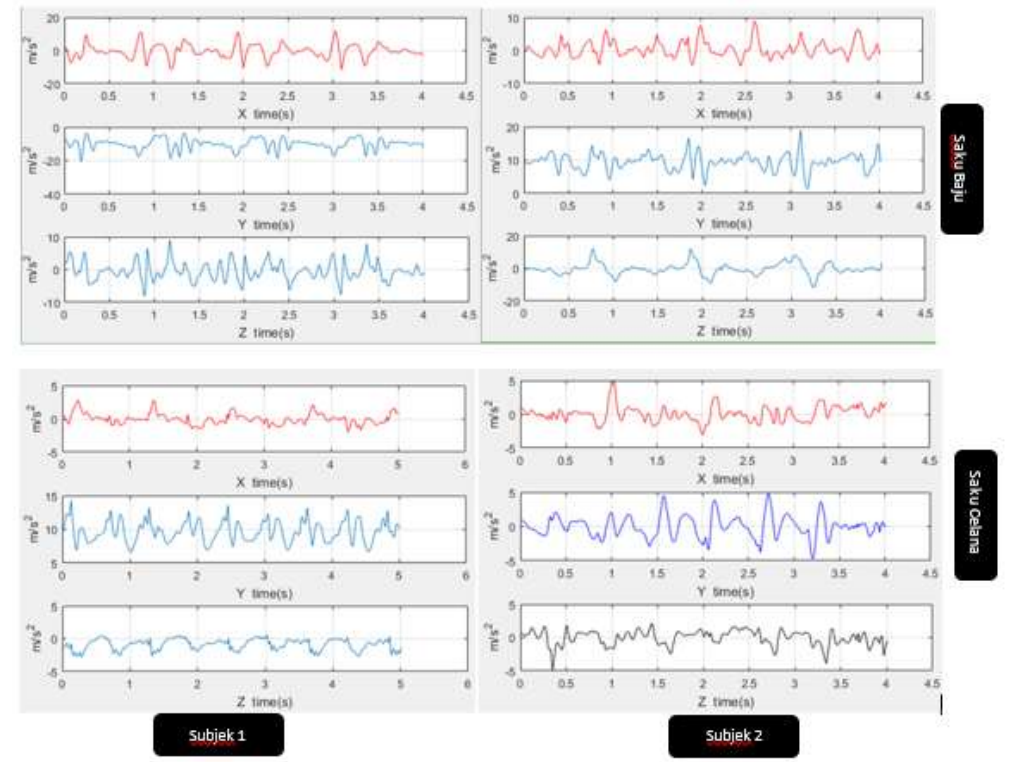

Gambar 2. Sinyal Aktivitas Berjalan
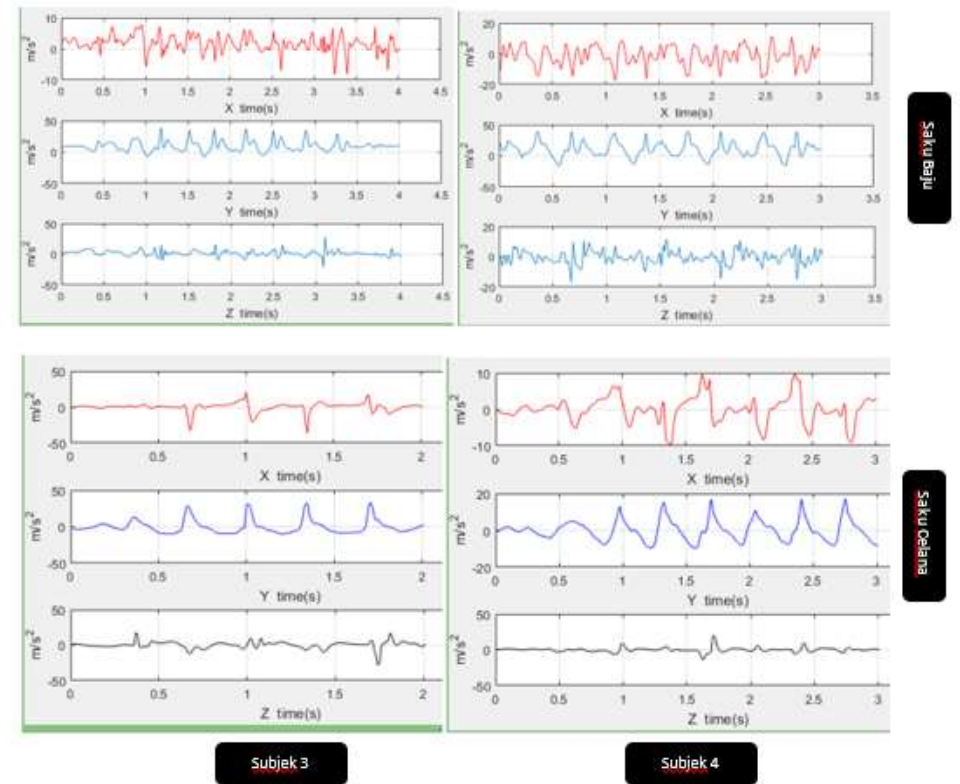

Subjek 3

Subjek 4

Gambar 3. Sinyal Aktivitas Berlari

Berdasarkan hasil ekstraksi, diperoleh fitur-fitur sinyal percepatan linier untuk penempatan smartphone dalam saku baju dan saku sisi celana. Tabel 1 menunjukkan hasil ekstraksi fitur domain waktu sinyal untuk penempatan smartphone dalam saku celana, sedangkan tabel 5 menunjukkan hasil ekstraksi fitur domain frekuensi.

Tabel 1. Hasil Ekstraksi Sinyal Domain Waktu Pada Saku Celana

\begin{tabular}{lcccccccccc}
\hline \multicolumn{1}{c}{ Fitur } & Duduk & Berdiri & $\begin{array}{c}\text { Ber } \\
\text { baring }\end{array}$ & Berjalan & Berlari & Lompat & $\begin{array}{c}\text { Naik } \\
\text { tangga }\end{array}$ & $\begin{array}{c}\text { Turun } \\
\text { tangga }\end{array}$ & $\begin{array}{c}\text { Ber } \\
\text { sepeda }\end{array}$ & $\begin{array}{c}\text { Gempa } \\
\text { bumi }\end{array}$ \\
\hline meanX & 1,965 & 1,725 & 1,951 & 0,782 & 0,906 & 1,047 & 0,913 & 0,668 & 0,732 & 0,003 \\
meanY & 2,180 & 2,081 & 2,773 & 0,845 & 1,147 & 1,741 & 1,353 & 1,055 & 0,992 & 0,010 \\
meanZ & 1,437 & 2,272 & 1,992 & 0,689 & 0,920 & 1,341 & 1,363 & 0,785 & 0,639 & 0,009 \\
medianX & 2,007 & 1,682 & 1,879 & 0,891 & 1,190 & 1,135 & 0,946 & 0,647 & 0,799 & 0,004 \\
medianY & 2,122 & 2,119 & 2,869 & 0,832 & 2,674 & 2,111 & 1,491 & 0,827 & 1,099 & 0,013 \\
medianZ & 1,454 & 2,256 & 1,948 & 0,707 & 1,065 & 1,587 & 1,631 & 0,965 & 0,651 & 0,010 \\
$\operatorname{maxX}$ & 3,302 & 2,450 & 4,401 & 7,314 & 14,382 & 17,267 & 5,451 & 6,383 & 5,678 & 0,018 \\
$\operatorname{maxY}$ & 3,040 & 2,970 & 3,881 & 7,878 & 20,349 & 18,925 & 8,906 & 9,630 & 5,588 & 0,038 \\
\hline
\end{tabular}


Tabel 2. Hasil Ekstraksi Sinyal Domain Frekuensi Pada Saku Celana

\begin{tabular}{|c|c|c|c|c|c|c|c|c|c|c|}
\hline Fitur & Duduk & Berdiri & $\begin{array}{c}\text { Ber } \\
\text { baring }\end{array}$ & Berjalan & Berlari & Lompat & $\begin{array}{c}\text { Naik } \\
\text { tangga }\end{array}$ & $\begin{array}{c}\text { Turun } \\
\text { tangga }\end{array}$ & $\begin{array}{c}\text { Ber } \\
\text { sepeda }\end{array}$ & $\begin{array}{c}\text { Gempa } \\
\text { bumi }\end{array}$ \\
\hline fdomX & 0,143 & 0,189 & 0,196 & 0,420 & 1,060 & 0,910 & 0,462 & 0,512 & 0,898 & 2,900 \\
\hline fdomY & 0,187 & 0,128 & 0,144 & 0,560 & 1,222 & 0,627 & 0,499 & 0,506 & 0,533 & 2,348 \\
\hline fdomZ & 0,277 & 0,091 & 0,219 & 0,703 & 2,104 & 1,091 & 0,495 & 0,524 & 0,771 & 2,322 \\
\hline energyX & 104,174 & 76,507 & 121,372 & 104,512 & 446,819 & 460,488 & 66,465 & 66,279 & 74,192 & 0,006 \\
\hline energyY & 90,372 & 81,647 & 131,405 & 131,676 & 1077,408 & 835,306 & 180,424 & 179,515 & 86,075 & 0,367 \\
\hline energyZ & 57,859 & 104,276 & 99,338 & 119,497 & 402,179 & 461,418 & 114,307 & 89,271 & 32,177 & 0,193 \\
\hline centroidX & 6,338 & 5,956 & 7,566 & 9,953 & 12,482 & 12,841 & 11,117 & 11,644 & 10,624 & 43,546 \\
\hline centroidY & 5,102 & 4,359 & 5,483 & 9,762 & 10,384 & 9,830 & 8,921 & 9,298 & 8,833 & 40,669 \\
\hline centroidZ & 6,451 & 4,823 & 8,002 & 10,962 & 16,679 & 15,047 & 11,043 & 12,392 & 12,946 & 44,262 \\
\hline entropyX & 1,640 & 1,693 & 1,813 & 1,957 & 1,538 & 1,695 & 2,060 & 2,264 & 1,943 & 1,210 \\
\hline entropyY & 1,070 & 1,324 & 0,728 & 1,947 & 1,340 & 1,501 & 1,556 & 1,959 & 1,762 & 1,227 \\
\hline entropyZ & 1,807 & 1,239 & 1,274 & 2,036 & 1,638 & 1,632 & 1,566 & 1,942 & 2,390 & 1,176 \\
\hline meanfreqX & 1,898 & 1,863 & 2,543 & 5,041 & 6,686 & 7,455 & 5,489 & 5,999 & 5,427 & 2,900 \\
\hline meanfreqY & 1,402 & 1,398 & 1,279 & 5,170 & 4,848 & 4,980 & 3,944 & 4,542 & 3,580 & 2,348 \\
\hline meanfreqZ & 2,384 & 1,321 & 2,677 & 5,370 & 11,514 & 9,833 & 4,582 & 7,396 & 7,523 & 2,322 \\
\hline $\max Z$ & 2,579 & 3,302 & 3,832 & 8,416 & 18,474 & 19,272 & 7,677 & 8,069 & 3,375 & 0,032 \\
\hline $\min X$ & 3,141 & $-2,898$ & 4,332 & 7,166 & $-14,725$ & 17,091 & $-6,509$ & 5,984 & 5,097 & $-0,016$ \\
\hline $\min Y$ & 3,029 & 2,796 & 4,223 & $-8,117$ & 19,129 & 17,651 & 8,385 & 9,587 & $-5,598$ & $-0,024$ \\
\hline $\min Z$ & $-3,285$ & 2,883 & $-4,186$ & 8,063 & 17,680 & 15,653 & 6,850 & $-8,463$ & $-3,764$ & $-0,017$ \\
\hline skewnessX & 0,941 & 0,643 & 0,701 & 0,621 & 0,603 & 0,664 & 0,925 & 0,859 & 0,372 & $-0,062$ \\
\hline skewnessY & 0,493 & 0,666 & 0,593 & 0,654 & 0,708 & 0,992 & 0,679 & 1,373 & 0,407 & $-0,103$ \\
\hline skewnessZ & 0,837 & 0,715 & 0,709 & 0,607 & 0,825 & 0,663 & 1,013 & 0,944 & 0,349 & $-0,019$ \\
\hline kurtosisX & 4,342 & 3,311 & 4,174 & 3,962 & 3,834 & 5,098 & 5,568 & 4,868 & 2,929 & 1,126 \\
\hline kurtosisY & 2,867 & 3,145 & 3,171 & 4,387 & 3,164 & 4,617 & 4,087 & 5,958 & 2,937 & 1,228 \\
\hline kurtosisZ & 4,706 & 3,848 & 4,048 & 4,277 & 6,328 & 5,732 & 5,256 & 6,556 & 3,250 & 1,088 \\
\hline
\end{tabular}

Tabel 4 memperlihatkan perbedaan karakteristik yang cukup signifikan antara sinyal aktivitas manusia dan sinyal gempa bumi dalam domain waktu. Sinyal percepatan linier akibat aktivitas manusia memiliki nilai yang lebih besar untuk semua fitur dibandingkan dengan sinyal gempa bumi. Distribusi sinyal percepatan aktivitas manusia cenderung bersifat leptokurtic (puncak distribusi runcing), sedangkan sinyal gempa bumi cenderung bersifat platykurtic (puncak distribusi tumpul). Sebagian besar sinyal aktivitas manusia memiliki amplitudo yang lebih besar dibanding sinyal gempa bumi. Hal ini ditunjukkan oleh fitur nilai maksimum untuk semua sumbu akselerometer pada sinyal aktivitas manusia.

Tabel 5 juga memperlihatkan perbedaan karakteristik yang signifikan antara sinyal aktivitas manusia dan sinyal gempa bumi dalam domain frekuensi. Sebagian besar fitur domain frekuensi menunjukkan perbedaan nilai yang menonjol, kecuali nilai entropi dan frekuensi rerata. Perbedaan arakteristik yang sangat signifikan ditunjukkan oleh fitur frekuensi dominan dan energi sinyal. Frekuensi dominan sinyal aktivitas manusia cenderung lebih kecil dibanding frekuensi dominan sinyal gempa bumi bermagnitudo kuat, tetapi energi sinyal aktivitas manusia jauh lebih besar dibanding energi sinyal gempa bumi yang terekam oleh akselerometer.

Tabel 3. Hasil Ekstraksi Sinyal Domain Waktu Pada Saku Baju

\begin{tabular}{lcccccccccc}
\hline \multicolumn{1}{c}{ Fitur } & Duduk & Berdiri & $\begin{array}{c}\text { Ber } \\
\text { baring }\end{array}$ & $\begin{array}{c}\text { Berjal } \\
\text { an }\end{array}$ & Berlari & Lompat & $\begin{array}{c}\text { Naik } \\
\text { tanga }\end{array}$ & $\begin{array}{c}\text { Turun } \\
\text { tangga }\end{array}$ & $\begin{array}{c}\text { Ber } \\
\text { sepeda }\end{array}$ & $\begin{array}{c}\text { Gempa } \\
\text { bumi }\end{array}$ \\
\hline meanX & 0,396 & 0,379 & 0,382 & 0,431 & 0,384 & 0,360 & 0,471 & 0,454 & 0,500 & 0,003 \\
meanY & 1,019 & 0,649 & 0,754 & 0,571 & 0,473 & 0,504 & 0,569 & 0,716 & 0,927 & 0,010 \\
meanZ & 0,668 & 0,580 & 0,564 & 0,796 & 0,417 & 0,508 & 0,576 & 0,504 & 0,652 & 0,009 \\
medianX & 0,490 & 0,510 & 0,443 & 0,719 & 0,478 & 0,669 & 0,643 & 0,660 & 0,621 & 0,004 \\
medianY & 1,658 & 1,175 & 1,376 & 1,187 & 1,618 & 1,734 & 2,024 & 2,328 & 2,475 & 0,013 \\
$\operatorname{medianZ}$ & 0,837 & 0,878 & 0,803 & 1,158 & 0,753 & 0,911 & 1,263 & 1,280 & 1,389 & 0,010 \\
$\operatorname{maxX}$ & 2,035 & 2,194 & 2,922 & 2,986 & 2,721 & 3,288 & 4,219 & 5,304 & 5,504 & 0,018 \\
$\operatorname{maxY}$ & 5,958 & 5,830 & 7,695 & 5,716 & 6,279 & 5,699 & 13,263 & 8,207 & 10,58 & 0,038 \\
\hline
\end{tabular}




\begin{tabular}{lcccccccccc}
\hline \multicolumn{1}{c}{ Fitur } & Duduk & Berdiri & $\begin{array}{c}\text { Ber } \\
\text { baring }\end{array}$ & $\begin{array}{c}\text { Berjal } \\
\text { an }\end{array}$ & Berlari & Lompat & $\begin{array}{c}\text { Naik } \\
\text { tanga }\end{array}$ & $\begin{array}{c}\text { Turun } \\
\text { tangga }\end{array}$ & $\begin{array}{c}\text { Ber } \\
\text { sepeda }\end{array}$ & $\begin{array}{c}\text { Gempa } \\
\text { bumi }\end{array}$ \\
\hline $\boldsymbol{m a x Z}$ & 2,631 & 3,211 & 3,394 & 3,079 & 3,464 & 4,238 & 5,082 & 7,681 & 8,781 & 0,032 \\
$\min X$ & 1,938 & 1,937 & 2,227 & 2,493 & 2,658 & 2,687 & $-4,777$ & 4,544 & 4,882 & $-0,016$ \\
$\min Y$ & $-6,398$ & 4,960 & 7,328 & 5,376 & $-6,459$ & $-6,616$ & 6,264 & $-12,26$ & $-12,74$ & $-0,024$ \\
$\quad \operatorname{minZ}$ & 2,482 & 2,460 & $-3,629$ & $-4,026$ & 3,343 & 2,914 & $-6,679$ & 6,760 & 7,451 & $-0,017$ \\
skewnessX & 0,666 & 0,470 & 0,765 & 0,594 & 0,979 & 0,879 & 0,795 & 0,737 & 0,922 & $-0,062$ \\
skewnessY & 0,140 & 0,160 & 0,393 & 0,206 & 0,256 & 0,267 & 0,745 & 0,796 & 0,952 & $-0,103$ \\
skewnessZ & 0,550 & 0,507 & 0,837 & 0,647 & 1,065 & 0,790 & 0,999 & 0,938 & 1,022 & $-0,019$ \\
kurtosisX & 3,055 & 2,654 & 3,434 & 3,200 & 4,477 & 4,283 & 3,906 & 4,149 & 4,705 & 1,126 \\
kurtosisY & 1,362 & 1,339 & 1,836 & 1,410 & 1,461 & 1,448 & 2,889 & 3,044 & 3,530 & 1,228 \\
kurtosisZ & 2,689 & 2,677 & 3,870 & 3,049 & 4,400 & 3,166 & 4,453 & 4,326 & 5,135 & 1,088 \\
\hline
\end{tabular}

Tabel 3 dan tabel 4 menunjukkan sinyal aktivitas manusia untuk smartphone yang diletakkan pada saku baju juga memiliki perbedaan karakteristik yang signifikan dibandingkan sinyal gempa bumi, baik dalam domain waktu maupun frekuensi. Namun demikian, sebagian besar nilai fitur sinyal akselerometer smartphone yang diletakkan pada saku celana memiliki nilai yang lebih tinggi dibanding yang diletakkan pada saku baju. Hal ini disebabkan oleh perpindahan posisi kaki yang lebih besar dibanding perpindahan posisi badan bagian dada saat beraktivitas.

Tabel 4. Hasil Ekstraksi Sinyal Domain Frekuensi Pada Saku Baju

\begin{tabular}{lcccccccccc}
\hline \multicolumn{1}{c}{ Fitur } & Duduk & Berdiri & $\begin{array}{c}\text { Ber } \\
\text { baring }\end{array}$ & Berjalan & Berlari & Lompat & $\begin{array}{c}\text { Naik } \\
\text { tangga }\end{array}$ & $\begin{array}{c}\text { Turun } \\
\text { tangga }\end{array}$ & $\begin{array}{c}\text { Ber } \\
\text { sepeda }\end{array}$ & $\begin{array}{c}\text { Gempa } \\
\text { bumi }\end{array}$ \\
\hline fdomX & 0,143 & 0,189 & 0,196 & 0,420 & 1,060 & 0,910 & 0,462 & 0,512 & 0,898 & 2,900 \\
fdomY & 0,187 & 0,128 & 0,144 & 0,560 & 1,222 & 0,627 & 0,499 & 0,506 & 0,533 & 2,348 \\
fdomZ & 0,277 & 0,091 & 0,219 & 0,703 & 2,104 & 1,091 & 0,495 & 0,524 & 0,771 & 2,322 \\
energyX & 104,174 & 76,507 & 121,372 & 104,512 & 446,819 & 460,488 & 66,465 & 66,279 & 74,192 & 0,006 \\
energyY & 90,372 & 81,647 & 131,405 & 131,676 & 1077,408 & 835,306 & 180,424 & 179,515 & 86,075 & 0,367 \\
energyZ & 57,859 & 104,276 & 99,338 & 119,497 & 402,179 & 461,418 & 114,307 & 89,271 & 32,177 & 0,193 \\
centroidX & 6,338 & 5,956 & 7,566 & 9,953 & 12,482 & 12,841 & 11,117 & 11,644 & 10,624 & 43,546 \\
centroidY & 5,102 & 4,359 & 5,483 & 9,762 & 10,384 & 9,830 & 8,921 & 9,298 & 8,833 & 40,669 \\
centroidZ & 6,451 & 4,823 & 8,002 & 10,962 & 16,679 & 15,047 & 11,043 & 12,392 & 12,946 & 44,262 \\
entropyX & 1,640 & 1,693 & 1,813 & 1,957 & 1,538 & 1,695 & 2,060 & 2,264 & 1,943 & 1,210 \\
entropyY & 1,070 & 1,324 & 0,728 & 1,947 & 1,340 & 1,501 & 1,556 & 1,959 & 1,762 & 1,227 \\
entropyZ & 1,807 & 1,239 & 1,274 & 2,036 & 1,638 & 1,632 & 1,566 & 1,942 & 2,390 & 1,176 \\
meanfreqX & 1,898 & 1,863 & 2,543 & 5,041 & 6,686 & 7,455 & 5,489 & 5,999 & 5,427 & 2,900 \\
meanfreqY & 1,402 & 1,398 & 1,279 & 5,170 & 4,848 & 4,980 & 3,944 & 4,542 & 3,580 & 2,348 \\
meanfreqZ & 2,384 & 1,321 & 2,677 & 5,370 & 11,514 & 9,833 & 4,582 & 7,396 & 7,523 & 2,322 \\
\hline
\end{tabular}

Hasil ekstraksi sinyal selanjutnya diklasifisikan menggunakan algoritma K-NN. Algoritma ini diterapkan untuk masing-masing penempatan smartphone. Tabel 5 menyatakan nilai akurasi algoritma K-NN untuk penempatan smartphone di saku baju dan untuk penempatan smartphone di saku sisi celana. Hasil menunjukkan bahwa algoritma Fine $K$-NN memiliki akurasi tertinggi, baik untuk sinyal akselerometer smartphone yang diletakkan pada saku celana maupun saku baju. Jika nilai $\mathrm{K}$ atau jumlah tetangga terdekat semakin banyak, maka tingkat akurasi algoritma semakin rendah. Hal ini terlihat dengan tingkat akurasi yang menurun dari Medium K-NN ke Coarse $K$ - $N N$. Banyaknya jumlah tetangga terdekat sebagai prediktor justru semakin menambah tingkat ambiguitas algoritma dalam menentukan kelas input sinyal. Penentuan jarak antar tetangga terdekat menggunakan Euclidean Distance lebih baik dibanding Cosine Metric Distance maupun Cubic Metric Distance. Hal ini dibuktikan dengan akurasi Fine K-NN, Medium $K-N N$ dan Coarse $K-N N$ yang lebih tinggi dibanding Cosine $K-N N$ dan Cubic K-NN. Penempatan smartphone pada saku celana memiliki akurasi prediksi yang lebih tinggi dibanding penempatan smartphone pada saku baju, karena sinyal akselerometer pada saku celana memiliki karakteristik yang lebih signifikan dibanding sinyal akselerometer pada saku baju. 
Tabel 5. Nilai Akurasi Algoritma K-NN

\begin{tabular}{lcccccc}
\hline \multirow{2}{*}{$\begin{array}{c}\text { Tipe Algoritma } \\
\text { K-NN }\end{array}$} & \multicolumn{3}{c}{ Saku Celana } & \multicolumn{3}{c}{ Saku Baju } \\
\cline { 2 - 7 } & $\begin{array}{c}\text { True } \\
(\boldsymbol{T P}+\boldsymbol{T N})\end{array}$ & $\begin{array}{c}\text { False } \\
(\boldsymbol{F P}+\boldsymbol{F N})\end{array}$ & $\begin{array}{c}\text { Akurasi } \\
(\%)\end{array}$ & $\begin{array}{c}\text { True } \\
(\boldsymbol{T P}+\boldsymbol{T N})\end{array}$ & $\begin{array}{c}\text { False } \\
(\boldsymbol{F P}+\boldsymbol{F N})\end{array}$ & $\begin{array}{c}\text { Akurasi } \\
(\%)\end{array}$ \\
\hline Fine K-NN & 1919 & 0 & 100 & 1838 & 0 & 100 \\
Medium K-NN & 1482 & 437 & 77,2 & 1246 & 592 & 67,8 \\
Coarse K-NN & 1478 & 441 & 77 & 1152 & 686 & 62,7 \\
Cosine K-NN & 1458 & 461 & 76 & 1244 & 594 & 67,7 \\
Cubic K-NN & 1470 & 449 & 76,6 & 1230 & 608 & 66,9 \\
\hline
\end{tabular}

Nilai akurasi setiap tipe algoritma K-NN dianalisis melalui confusion matrix. Confusion matrix menyatakan tingkat ambiguitas algoritma dalam mengklasifikasikan sinyal menurut jenis aktivitas manusia maupun sinyal gempa bumi. Nomor kelas dari 1 hingga 10 berturut-turut adalah duduk, berdiri, berbaring, berjalan, berlari, melompat, naik tangga, turun tangga, bersepeda, dan non-HAR, sedangkan nomor kelas 11 adalah sinyal gempa bumi. Gambar 8 menunjukkan confusion matrix untuk setiap tipe algoritma K-NN.
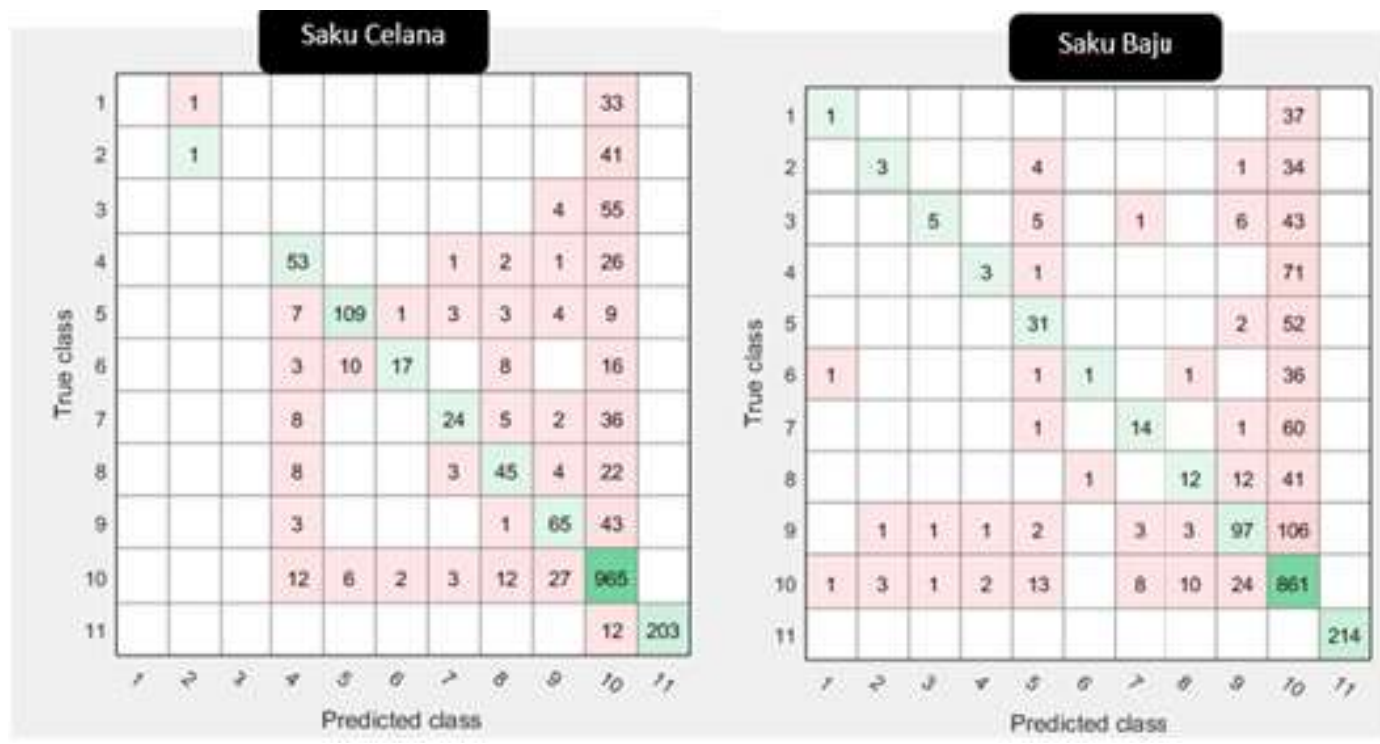

Gambar 8. Confusion Matrix Fine K-NN

Gambar 8 menunjukkan bahwa algoritma K-NN secara umum mampu memilah sinyal akselerometer smartphone akibat aktivitas manusia dan sinyal gempa bumi dengan baik. Sebagian besar input sinyal gempa bumi dapat diklasifikasikan secara benar, meskipun terdapat beberapa kesalahan prediksi sebagai sinyal non-HAR. Kesalahan prediksi ini terjadi ketika smartphone akan dipindahkan dari atau ke saku celana. Sinyal non-HAR juga menyebabkan sebagian besar kesalahan prediksi untuk sinyal aktivitas lainnya. Pola sinyal non-HAR ini sangat beragam serta bersifat sangat acak dan kemungkinan menyamai pola sinyal aktivitas yang lain. Hal ini menyebabkan tingkat ambiguitas algoritma K-NN terhadap kelas sinyal tersebut meningkat, sehingga menimbulkan kesalahan prediksi. Gambar 9 menunjukkan hasil klasifikasi berbagai sinyal aktivitas manusia dan sinyal gempa bumi menggunakan algoritma K-NN pada Graphical User Interface. 




Gambar 9. Graphical User Interface HAR

\section{KESIMPULAN}

Berdasarkan hasil pengujian Human Activity Recognizer sebagai classifier sinyal gempa bumi dan sinyal aktivitas manusia pada akselerometer smartphone Android menggunakan algoritma K-Nearest Neighbor diperoleh beberapa simpulan sebagai berikut:

a. Hasil penghimpunan data menunjukkan bahwa sinyal akselerometer smartphone memiliki pola tertentu untuk setiap jenis aktivitas manusia.

b. Perbedaan karakteristik sinyal aktivitas manusia dan sinyal gempa bumi cukup signifikan baik dalam domain waktu maupun frekuensi.

c. Algoritma $K-N N$ secara umum mampu memilah sinyal akselerometer smartphone akibat aktivitas manusia dan sinyal gempa bumi dengan rentang akurasi $66,9 \%$ hingga $100 \%$.

d. Algoritma tipe Fine K-NN memiliki akurasi tertinggi dalam perancangan Human Activity Recognizer menggunakan algoritma K-NN.

e. Penambahan pola peletakan smartphone pada saku baju maupun saku celana, sehingga bersifat dinamis.

\section{DAFTAR PUSTAKA}

[1] Agrawal, et al. 2015. "Human Activity Recognition Data Mining Project”. Scientific Article. Carnegie Mellon University.

[2] Anguita, et al. 2013. "A Public Domain Dataset for Human Activity Recognition Using Smartphones". ESANN 2013 proceedings, European Symposium on Artificial Neural Networks, Computational Intelligence and Machine Learning, ISBN 978-2-87419-081-0, 437-442.

[3] Bayat, Pomplun dan Tran. 2014. "A Study on Human Activity Recognition Using Accelerometer Data from Smartphones". The $11^{\text {th }}$ International Conference on Mobile Systems and Pervasive Computing (MobiSPC2014), Procedia Computer Science, 450-457.

[4] BMKG. 2012. Gempa Bumi Edisi Populer. Jakarta: BMKG.

[5] Bramer. 2007. Principles of Data Mining. London: Springer.

[6] Cope, Eric. 2009. "Estimating Human Movement Using a Three Axis Accelerometer". A Qualifying Examination Presented in Partial Fullfilment of the Requirements for the Degree Doctor of Philosophy, Department of Electrical Engineering, Arizona State University.

[7] Sholahudin, Hadi dan Supriana. 2010. "Penerapan Metode Liniear Discriminant Analysis Pada Pengenalan Wajah Berbasis Kamera". Konferensi Nasional Matematika, UNIMA.

[8] Sumarlin. 2015. "Implementasi Algoritma K-Nearest Neighbor Sebagai Pendukung Keputusan Klasifikasi Penerima Beasiswa PPA dan BBM". Jurnal Sistem Informasi Bisnis, Volume I, 52-62.

[9] Suto, Onigo dan Sitar. 2017. "Feature Analysis to Human Activity Recognition". International Journal of Computers, Communications \& Control (IJCCC), ISSN 1841-9836, 116-130.

[10] Vitola, et al. 2017. "A Sensor Data Fusion System Based on k-Nearest Neighbor Pattern Classification for Structural Health Monitoring Applications". Jurnal Sensors, MDPI. 